\title{
A Arte da Bibliografia: uma pequena apresentação
}

\author{
The Art of Bibliography: a short introduction
}

\begin{abstract}
Giulia Crippa
Livre Docente em Ciência da Informação pela Faculdade de Filosofia, Ciências e Letras de Ribeirão Preto -

FFCLRP/USP.

Professora do curso de Biblioteconomia e Ciências da Informação e da Documentação da FFCLRP/USP.

E-mail: giuliac@ffclrp.usp.br
\end{abstract}

O seminário internacional $A$ arte da bibliografia surgia de uma ideia entre alguns docentes e pesquisadores da área da Ciência da Informação em meados de 2013. As primeiras conversas levaram a pensar a Bibliografia como a (infra)estrutura de toda a ciência moderna. Sua condição "infra" pode ser interpretada não como "algo embaixo de", mas como o mosaico que sustenta as práticas de investigação e dá vida às suas dinâmicas. O caráter "infra", no entanto, torna-a "silenciada" em diferentes discursos.

À busca por iluminar o pensamento bibliográfico e por demonstrar não apenas sua condição infraestrutural, mas também, na outra margem, sua condição de modo de ver, de perceber, de reconhecer e de apresentar o conhecimento, buscamos reunir pesquisadores de universidades brasileiras e estrangeiras como USP, UNIRIO, IBICT, UNB, UFMG, UFRJ, os arquivos do Mundaneum de Bruxela, a Universidade de Bolonha e de Roma "La Sapienza" entre outras instituições nacionais e internacionais, para colocar a Bibliografia, em debate no ano de 2014 e de 2015. A partir do "I Seminário Internacional A Arte da Bibliografia", no Rio de Janeiro, em 2014, consolidou-se a proposta de construção do fórum permanente de estudos bibliográficos, com o mesmo nome, sustentado pela pesquisa desenvolvida pelos trabalhos de dois grupos de pesquisa cadastrados no CNPq, o Ecce Líber ê o Biblioteca disciplinatha, que agregam pesquisadores nacionais e internacionais de várias áreas ligadas ao livro e à bibliografia.

O desafio do "II Seminário Internacional A Arte da Bibliografia" foi atravessar, passo a passo, os estudos que envolvem o Biblion como objeto de interesse da atividade de organização própria das disciplinas de biblioteconomia mas que envolve, também, reflexões e pesquisas de outras áreas, como a história e a própria arte.

Ao longo dos séculos, os estudos bibliográficos apontaram tipologias documentárias muito diferentes entre si: codex, volumen, livros impressos, jornais, audiovisuais e, hoje, 
documentos digitais. Esses últimos possuem características absolutamente inovadoras em relação a seus antecedentes, a ponto de colocar em crise muitas questões bem consolidadas tanto em relação à sua descrição como à sua gestão.

Acostumados no mundo analógico a separar fisicidade e conteúdo, texto e paratexto, com o documento digital nos encontramos em uma dimensão original que desarruma a relação entre suporte material e escrita. Os documentos são "inscrições" de qualquer forma gravadas sobre qualquer suporte. A biblioteca, por si, em geral privilegia documentos "publicados", isso é: pensados e realizados para ter circulação.

Trata-se de propriedades que tornam o livro enquanto texto (apesar das mudanças materiais de sua manifestação) a marca de comparação para todas as tipologias documentárias, o crivo para que sejam ou não inseridas em uma coleção e oportunamente catalogadas.

A descrição bibliográfica é, antes de tudo, visão de mundo. Explica-se, assim, a contradição aparente de aplicá-la ao que não é livro. A dificuldade de descrição de muitos documentos revela a necessidade de revisão dos sistemas, não uma abordagem metodológica errada.

As carências dos sistemas de mediação bibliográfica levaram à formulação de novas linguagens descritivas menos dependentes do "livro" entendido como objeto. Disso não decorre necessariamente a remoção integral de todos os elementos que, tradicionalmente, permitiram identificar as propriedades do livro entendido como texto, no meio de todas as outras tipologias documentárias.

Todas essas questões mobilizaram os estudiosos já desde o primeiro evento, realizado no Rio em dezembro de 2014, com ampla participação de público. A bibliografia, já na primeira edição do seminário, foi enfocada por múltiplas perspectivas, ligadas à história do livro, ao livro de artista, aos catálogos de livros raros e às necessidades de se repensar as atividades bibliográficas em um quadro em que o mundo digital apresenta necessidades inovadoras e desafiadoras de novas concepções "cartográficas" da informação e do conhecimento. Na primeira edição teve uma intensa troca de pesquisas entre várias instituições, com a exposição de trabalhos sobre os temas que afloraram, e revelou, principalmente, a orientação dos estudos cariocas em diálogo com pesquisadores de outras regiões do Brasil (São Paulo, Brasília, Belo Horizonte, além das enriquecedoras reflexões sobre a riqueza bibliográfica dos arquivos de Paul 
Otlet). Os principais resultados foram reunidos e publicados pela revista Informação $e$ Informação de Londrina, em um número especial inteiramente dedicado ao evento.

A repercussão do evento incentivou os idealizadores a buscar as possibilidades de dar continuidade ao evento em 2015. Dessa vez, resolvemos que o evento devia ser itinerante, para permitir que as várias escolas expusessem a orientação dos trabalhos dedicados à bibliografia de maneira a desenvolver o diálogo que se iniciara no Rio de Janeiro. Foi, assim, definida a cidade de São Paulo, no campus da USP, a sede da segunda edição da Arte da Bibliografia, contando com o apoio da Escola de Comunicação e Arte da universidade.

Dessa vez, o "tom" da discussão foi dado pelas pesquisas sênior e de pós-graduação principalmente paulistas, mas sempre na ótica de manter o debate vivo e aberto entre todas as instituições, além de mantê-lo altamente internacional. A conferência de abertura contou com a fala de Alfredo Serrai, professor emérito da universidade de Roma "La Sapienza", uma das máximas autoridades mundiais no campo da Bibliografia Histórica, autor e organizador da obra de referência mais completa sobre o tema, a História da Bibliografia ${ }^{l}$ em dez volumes, publicada pela editora Bulzoni de Roma. Uma conferência que, com certeza, reforçou as questões que os pesquisadores brasileiros já vinham trabalhando desde o ano anterior, envolvendo epistemologia e fenomenologia da bibliografia.

Os pesquisadores presentes abriram o amplo leque dos estudos bibliográficos em direções variadas e foi possível observar um aspecto interessante que envolve duas das escolas envolvidas na iniciativa: de um lado, em 2014, a prevalência dos estudos cariocas revelou um foco maior na bibliografia do século XIX; do outro, a experiência paulista revelou um certo pendor para o século XX. De qualquer maneira, o que resultou claramente dos dois eventos foi que não somente existe uma necessidade de problematizar, ampliar e refinar as práticas e os conceitos que definem a bibliografia, mas que as questões relativas à bibliografia extrapolam, necessariamente, os limites e as fronteiras colocadas pela biblioteconomia, envolvendo também historiadores, comunicadores e artistas.

O evento encerrou-se com uma segunda conferência internacional, ministrada por uma grande estudiosa do bibliógrafo Conrad Gesner, Fiammetta Sabba, em que resultou evidente o cruzamento entre as reflexões mais contemporâneas sobre práticas bibliográficas e as contribuições que a história pode fornecer-lhes.

${ }^{1}$ SERRAI, Alfredo (Org.) História da bibliografia. Roma: Bulzoni, 1988-1999. 10 v. InCID: R. Ci. Inf. e Doc., Ribeirão Preto, v. 7, n. esp., p. 3-6, ago. 2016. 
A Arte da Bibliografia: uma pequena apresentação

Nos parece que o seminário $A$ arte da bibliografia vai de encontro ao questionamento de Darnton, que na década de 1990 afirmava que

Os livros, quando tratados como objetos de estudo, também se recusam a ficar
confinado dentro dos limites de uma única disciplina. Nenhuma delas - a história, a
literatura, a economia, a sociologia, a bibliografia - é capaz de fazer justiça a todos os
aspectos da vida de um livro. Pela sua própria natureza, portanto, a história dos livros
deve operar em escala internacional e com método interdisciplinar. (DARNTON,
1995, p.130-131)

Com essas ideias bem claras na base de nossas reflexões, estamos assim propondo, aqui, uma seleção dos trabalhos apresentados em São Paulo, no auditório da FEA/USP de São Paulo, que nos recepcionou de braços abertos, mostrando como esse dialogo bibliográfico se enreda pelas bibliotecas de todas as áreas. As apresentações completa do evento foram gravadas e estão disponíveis, em internet, na página http://iptv.usp.br/portal/video.action?idItem=32287.

Para 2016 as atividades do seminário internacional "A arte da bibliografia” já estão fervendo: apesar das inúmeras dificuldades em que se encontram as universidades e as agências de fomento, pretendemos dar continuidade ao evento, mantendo suas características de fórum privilegiado de alta qualidade para as pesquisas de ponta no campo da bibliografia. Nosso compromisso é que os centros onde os estudos bibliográficos acontecem hospedem o evento e, esse ano, ele deve acontecer em dezembro na escola de Ciência da Informação da UFMG, em Belo Horizonte. Já temos convidados internacionais garantidos e uma organização de altíssima qualidade destinada, certamente, a destacar mais uma vez os enriquecedores trabalhos dos pesquisadores envolvidos com pesquisas bibliográficas.

\section{Referencia}

DARNTON, Robert. O beijo de Lamourette. São Paulo: Companhia das Letras, 1995. 